\title{
Effect of using Mobile Sink on Chain-based Routing Protocols in Wireless Sensor Networks
}

\author{
Ahmed Salim \\ Math. Dept., \\ Fac. of Sci., \\ Univ. of Zagazig, Zagazig, \\ P. O. Box 44519, Egypt. \\ Math. Dept., \\ Faculty of Science and Arts, \\ Al-mithnab, Qassim University, \\ P. O. Box 931, Buridah 51931, \\ Al-mithnab, Kingdom of Saudi Arabia.
}

\author{
Asmaa Ahmed Badran \\ Math. Dept. \\ Univ. of Zagazig, Zagazig, Egypt.
}

\begin{abstract}
In this paper, we examine some protocols related to WSNs. To evaluate the efficiency of different routing schemes, we compare six chain based routing protocols; Power Efficient Gathering in Sensor Information Systems (PEGASIS), Power Efficient Gathering in Sensor Information System Extended (PEGASIS-E), Chain Oriented SEnsor Network (COSEN), Energy Efficient Chain Based Sensor Network (ECBSN), Improved Energy Efficient Chain Based Sensor Network (IECBSN), and Energy-Aware PEGASIS-Based Hierarchal Routing Protocol for Wireless Sensor Networks (EAPHRN). Two scenarios are discussed to compare the performances of chain based routing protocols; in the first scenario static sink is used and in the second one mobile sink is used. We perform analytical simulations in terms of network lifetime and average energy consumption.
\end{abstract}

\section{General Terms:}

Wireless Sensor Networks, Routing Protocols

\section{Keywords:}

chain-based routing protocols, static sink, mobile sink.

\section{INTRODUCTION}

Wireless sensor networks (WSNs) are consist of a large number of sensors deployed in a certain area. The sensors would transform physical data into a form that would make it easier for the user to understand [4].

The simplest approach to collect data from sensor nodes is direct one where each sensor node transmits the data directly to the sink which is located far away. The cost of data transmission from each sensor node to the sink is very high, thus nodes die quickly and hence reducing the lifetime of the network. One common way to decrease the energy consumption in the communications between sensors and static sink is using multihop forwarding instead of direct connection [11]. The advantage of using multihop communication is low power in transmitting data to a nearby sensor. However, one of the main problems of applying multihop paradigm in WSN is that the sensors around static sink deplete their energy very fast due to high forwarding data traffic which leads to the sink becomes unreachable and WSN is nonfunctional [11]. As an alternative to multihop communication, researchers have proposed to mobilize sinks to collect data from sensors [2]. When the sink is able to move, sensors can communicate with the sink when it is near to them, and so hop by hop delivery path of data becomes shorter. Mobile sink even can move close to nodes when the nodes energy is reduced. So the set of nodes near the mobile sink can change, which provide more balance of energy and as a result, network lifetime can increased and reliability/connectivity can be improved [15 16 19 27].

In this paper, our goal is to adding the concept of sink mobility in chain based routing protocols, like, PEGASIS, PEGASIS-E, COSEN, ECBSN, IECBSN, and EAPHRN, then analyzing these protocols in order to compare the performance in terms of network life time and average energy consumption. The rest of the paper is organized as follows: Section 2 briefly reviews related work. In Section 3 we introduce our problem statement and assumptions . The simulation of our approach is presented in Section 4 In Section 5. we conclude our work.

\section{RELATED RESEARCH}

Routing in WSNs is very challenging due to several characteristics that distinguish them from contemporary communication and wireless ad hoc networks [3, 13, 20]. Routing protocols proposed for WSNs can be divided into seven categories:Location-based Protocols, Data-centric Protocols, Hierarchical Protocols, Mobility-based Protocols, Multipath-based Protocols, 
Heterogeneity-based Protocols, and QoS-based protocols [22]. In this work, we focus on hierarchical protocols, specially we focus on chain based protocols that can be considered type of hierarchical protocols.

In context of hierarchical protocols, many researches in the last few years have explored clustering in WSN from different perspectives [22]. LEACH [26] is the first and most popular energy-efficient hierarchical clustering algorithm for WSNs that was proposed for reducing power consumption.

PEGASIS (Power-Efficient gathering in Sensor Information Systems) [12], is the first and most popular energy-efficient chainbased hierarchical clustering protocol. The main idea of the PEGASIS protocol is the formation of a chain among the sensor nodes so that each node will receive from and transmit to a close neighbor. Gathered data moves from node to node, get fused, and eventually a designated node transmits it to the BS. The PEGASIS protocol achieves improvement varies between 100 to $300 \%$ when $1 \%, 20 \%, 50 \%$ and $100 \%$ of nodes die in the deployed field compared to the LEACH protocol.

The work in [1] propose an efficient two phases routing protocol called CCBRP (Chain-Chain based routing protocol). CCBRP protocol divides a WSN into a number of chains, each chain is created by using greedy algorithm as in PEGASIS protocol. In the first phase of CCBRP, sensor nodes in each chain transmit data to their chain leader nodes in parallel. In the second phase, all chain leader nodes form a chain using greedy algorithm and choose randomly a leader node then all chain leader nodes send their data to this chosen leader node. The chosen leader node fuses the data and forwards it to the sink.

CCM (Chain-Cluster based mixed routing) protocol [24] makes full use of the advantages of LEACH and PEGASIS, and provides improved performance over both of them. CCM protocol mainly divides a WSN into a number of chains and runs in two phases. In the first phase, sensor nodes in each chain transmit data to their own chain head nodes in parallel, using an improved chain routing protocol. In the second phase, all chain head nodes grouped as a cluster in a self-organized manner, where they transmit fused data to a voted cluster head using the cluster based routing.

In [25], the authors proposed an improved energy efficient PEGASIS based protocol (PEGASIS-E). PEGASIS-E uses average distance among the sensor nodes as the criteria for chaining, thereby providing better performance in terms of energy dissipation and amount of information sent to BS. The simulation results obtained show that PEGASIS-E gives an increase in the network lifetime as compared to PEGASIS.

COSEN (Chain Oriented SEnsor Network) [17] reduces the latency associated with the original PEGASIS protocol by forming multiple smaller chains instead of a single longer chain. At first several small, fixed-length chains are constructed using the same distance-based greedy heuristic of the original PEGASIS protocol and a chain leader is selected in each chain based on the highest remaining energy. Leader nodes are selected for certain number of rounds. These chain leaders again form a higher-level chain and among those leaders one is chosen depending on the distance to the BS and remaining energy-level; to accumulate all data from the network and send that data to the BS at each round whereas other nodes only communicate with its neighbor in the chain.

Y.Song [28] proposed an Energy-Efficient Chain-Based routing protocol (EECB) that is an improvement over PEGASIS. EECB uses distances between nodes and the base station and remaining energy levels of nodes to decide which node will be the leader that takes charge of transmitting data to the base station. Energy Efficient Chain Based Sensor Network (ECBSN) [14] overcomes several problems of PEGASIS. ECBSN overcomes the problem of excessive delay, instead of one long chain in the network number of short chains are formed and every first node in a chain becomes a leader node. Thus, it ignores the suitable proportion of nodes energy and distance between node and base station which optimize the leader selection according to the various application environments. An improved ECBSN protocol called IECBSN is proposed in [21]. IECBSN adopts a new method of selection of leader nodes based on selection value parameter, which outperforms ECBSN. EAPHRN (Energy Aware PEGASIS Based Hierarchical Routing) [6] is a chain based routing protocol in which node does not connects to the next closest node but connects to a random node that is not far than the distance threshold. We aim to add the concept of sink mobility in chain based routing protocols, then analyzing these protocols in order to compare the performance in terms of network life time and average energy consumption. The work in [19] show that the use of a mobile sink moving along a calculated path around the application area can significantly reduce the number of messages received per individual node and hence increase node lifetime. In another similar work authors focused on maximizing the network lifetime of WSNs by using sink mobility [23]. Energy formula that determines the moving times of sink based on residual energy of sensor nodes and approach to calculates optimum path are proposed in [23], which results in increasing the network lifetime.

The work in [8] is similar to our work, the authors compare five clustering routing protocols; Low Energy Adaptive Clustering Hierarchy (LEACH), Threshold Sensitive Energy Efficient Sensor Network (TEEN), Distributed Energy Efficient Clustering (DEEC) and two variants of TEEN which are Clustering and Multi-Hop Protocol in Threshold Sensitive Energy Efficient Sensor Network (CAMPTEEN) and Hierarchical Threshold Sensitive Energy Efficient Sensor Network (H-TEEN). They introduce the mobility of sink in the five proposed protocols and compare their performance.

In [16], the authors develop the LEACH clustering algorithm to be used in mobile WSNs where the sink is able to move with the goal of finding the optimal path between cluster heads for the mobile sink, an optimization algorithm based on ant colonies is used.

MobiRoute routing protocol proposed a model with a path predictable mobile sink to improve the packet deliver ratio. The sink is located at any point of network and the pause time of sink is longer than movement time. It has enough time to gather the data from nearby nodes. In this protocol all nodes should know the topological changes created due to sink mobility [2].

In [5] Jafri et al. proposed mobility in multi-chain PEGASIS based protocol. In this work mobile sink is moved along its trajectory and stays for a sojourn time at sojourn location to guarantee complete data collection. This approach increased network lifetime to a distinct level, as compared to classical approaches. Chakrabarti et al. proposed a model for power saving in WSNs using predicable path of sink. The model is performed for networks only single hop communication is used and analyze the success in data collection, and quantify the power consumption of the network using queuing model [15]. The main difference between our work and [2,5 8,15$]$ is that our work provides analytical simulations in terms of network lifetime and average energy consumption for different chain based routing protocols.

\section{ASSUMPTIONS AND PROBLEM STATEMENT}

In this section, first, we provide our assumptions and then we provide description of the problem we handle. 


\subsection{Assumptions}

Our approach relies on the following key assumptions regarding the sensor field and sensor nodes:

(1) Each node is assigned a unique ID to help identify one node from other neighboring nodes.

(2) All nodes are assumed to be identical and randomly distributed., i.e., they are uniquely identifiable homogenous sensor nodes.

(3) The position of each and every node is known in any arbitrary global coordinate system possibly by using a localization system [7 9.18$]$.

(4) Mobile sink can move around wireless sensor networks far away and sink has enough amount of energy, memory, and processing power.

(5) The base station have the location information and the identification of all nodes in the network [12].

\subsection{Problem statement}

Our objective is to analyze the performance of chain based routing protocols when using a mobile sink. We compare chain based routing protocols such as PEGASIS, PEGASIS-E, COSEN, ECBSN,IECBSN, and EAPHRN by implementing the concept of sink mobility in them. Their performances are observed and compared. The position of sink is varied at different locations of the network area according to different mobility scenarios.

In the proposed scenarios we consider data collected by a single mobile sink travelling through proposed mobility scenario in the monitored region. Initially sink starts it movement from the initial position of the bounded services area. Sink changes its relative position according to the different mobility scenarios( random and predetermined) [11].

3.2.1 Random mobility scenario. In this scenario, the sink initially is placed randomly on the edge of the area. Then a destination is randomly chosen and the sink moves towards this destination .Upon arrival, the nodes pauses for $T_{\text {pause }}$ time and again chooses a new destination for the next movement. As a result, the sink is staying in a location for a certain period of time (pause time). Once pause time expires, it moves towards the new calculated position at the selected speed. Here we use pause time because sink needs to collect the data packets before change its position and we have taken long pause time equals to round period time.

3.2.2 Predetermined scenarios. we consider three different predetermined scenarios, rectangle, circle and middle path.

Rectangle mobility scenario in rectangle mobility scenario, the sink moves along rectangle trajectory along the boundary of the network and pauses to collect data during round period then moves to next point.

Middle path mobility scenario model in this model the sink moves back and forth along path at the middle of the network and pause for a period of time to collect data.

Circle mobility scenario in circle mobility scenario, the sink circles along the boundary of the network and pauses to collect data during round period then moves to next point in the next round.

While the sink is staying in a location for a certain period of time it broadcasts a start message to the network nodes. After receiving the start message each head node set their value and starts to send the data packets to the sink till receives the stop message. Just before sink changes its position, it broadcasts another message to reset the nodes and stop the transmission, to reduce the packet drop. After that sink changes to a new position and follow the same steps every time [10].

\section{SIMULATION RESULTS}

A simulator have been implemented using $\mathrm{C} \#$ to evaluate the performance of our proposed protocol. In our simulation, 100 sensor nodes are randomly deployed in a region of size $200 \mathrm{~m} \times$ $200 \mathrm{~m}$ on a two dimensional plane and are uniformly distributed with base station (static and mobile). In order to measure the energy consumption of sensor nodes, we use the same energy parameters and radio model as discussed in [26], wherein energy consumption is mainly divided into two parts: receiving and transmitting messages. The transmission energy consumption needs additional energy to amplify the signal depending on the distance to the destination. Thus, to transmit a $k$-bits message a distance $d$, the radio power consumption will be,

$$
E_{T x}(k, d)=\left\{\begin{array}{cc}
k E_{\text {elec }}+k \epsilon_{f s} d^{2} & d<d_{0} \\
k E_{\text {elec }}+k \epsilon_{m p} d^{4} & d \geq d_{0},
\end{array}\right.
$$

and to receive this message, the radio expends will be

$$
E_{R x}(k)=k * E_{\text {elec }} .
$$

Simulated model parameters are set as: $E_{\text {elec }}=50 \mathrm{~nJ} / \mathrm{bit}, \epsilon_{f s}=$ $10 \mathrm{pJ} / \mathrm{bit} / \mathrm{m}^{2}, \epsilon_{m p}=\frac{13}{10000} \mathrm{pJ} / \mathrm{bit} / \mathrm{m}^{4}, d_{0}=\sqrt{\epsilon_{f s} / \epsilon_{m p}}$, and the initial energy per node $=2 J$.

In two different scenarios as, Static Sink and Mobile Sink (random, rectangle, circle and middle path scenario), we use the following performance metrics to indicate the performance of routing protocols:

-Average Energy Consumption: It is the average energy consumed by all the nodes in sending, receiving and forwarding operations. The average energy consumption per round until the first node die can be estimated as:

$$
E_{\text {Average }}=\frac{\sum_{i=1}^{N} E_{i}}{r}
$$

Where $N$ is the number of sensor nodes in the considered WSN, and $r$ is the number of rounds.

-Network Lifetime: It is the time interval from the start of operation (of the sensor network) until the death of the first alive node.

Lorem ipsum dolor sit amet, consectetuer adipiscing elit. Ut purus elit, vestibulum ut, placerat ac, adipiscing vitae, felis. Curabitur dictum gravida mauris. Nam arcu libero, nonummy eget, consectetuer id, vulputate a, magna. Donec vehicula augue eu neque. Pellentesque habitant morbi tristique senectus et netus et malesuada fames ac turpis egestas. Mauris ut leo. Cras viverra metus rhoncus sem. Nulla et lectus vestibulum urna fringilla ultrices. Phasellus eu tellus sit amet tortor gravida placerat. Integer sapien est, iaculis in, pretium quis, viverra ac, nunc. Praesent eget sem vel leo ultrices bibendum. Aenean faucibus. Morbi dolor nulla, malesuada eu, pulvinar at, mollis ac, nulla. Curabitur auctor semper nulla. Donec varius orci eget risus. Duis nibh mi, congue eu, accumsan eleifend, sagittis quis, diam. Duis eget orci sit amet orci dignissim rutrum.

Nam dui ligula, fringilla a, euismod sodales, sollicitudin vel, wisi. Morbi auctor lorem non justo. Nam lacus libero, pretium at, 
lobortis vitae, ultricies et, tellus. Donec aliquet, tortor sed accumsan bibendum, erat ligula aliquet magna, vitae ornare odio metus a mi. Morbi ac orci et nisl hendrerit mollis. Suspendisse ut massa. Cras nec ante. Pellentesque a nulla. Cum sociis natoque penatibus et magnis dis parturient montes, nascetur ridiculus mus. Aliquam tincidunt urna. Nulla ullamcorper vestibulum turpis. Pellentesque cursus luctus mauris.

Nulla malesuada porttitor diam. Donec felis erat, congue non, volutpat at, tincidunt tristique, libero. Vivamus viverra fermentum felis. Donec nonummy pellentesque ante. Phasellus adipiscing semper elit. Proin fermentum massa ac quam. Sed diam turpis, molestie vitae, placerat a, molestie nec, leo. Maecenas lacinia. Nam ipsum ligula, eleifend at, accumsan nec, suscipit a, ipsum. Morbi blandit ligula feugiat magna. Nunc eleifend consequat lorem. Sed lacinia nulla vitae enim. Pellentesque tincidunt purus vel magna. Integer non enim. Praesent euismod nunc eu purus. Donec bibendum quam in tellus. Nullam cursus pulvinar lectus. Donec et mi. Nam vulputate metus eu enim. Vestibulum pellentesque felis eu massa.

Quisque ullamcorper placerat ipsum. Cras nibh. Morbi vel justo vitae lacus tincidunt ultrices. Lorem ipsum dolor sit amet, consectetuer adipiscing elit. In hac habitasse platea dictumst. Integer tempus convallis augue. Etiam facilisis. Nunc elementum fermentum wisi. Aenean placerat. Ut imperdiet, enim sed gravida sollicitudin, felis odio placerat quam, ac pulvinar elit purus eget enim. Nunc vitae tortor. Proin tempus nibh sit amet nisl. Vivamus quis tortor vitae risus porta vehicula.

Fusce mauris. Vestibulum luctus nibh at lectus. Sed bibendum, nulla a faucibus semper, leo velit ultricies tellus, ac venenatis arcu wisi vel nisl. Vestibulum diam. Aliquam pellentesque, augue quis sagittis posuere, turpis lacus congue quam, in hendrerit risus eros eget felis. Maecenas eget erat in sapien mattis porttitor. Vestibulum porttitor. Nulla facilisi. Sed a turpis eu lacus commodo facilisis. Morbi fringilla, wisi in dignissim interdum, justo lectus sagittis dui, et vehicula libero dui cursus dui. Mauris tempor ligula sed lacus. Duis cursus enim ut augue. Cras ac magna. Cras nulla. Nulla egestas. Curabitur a leo. Quisque egestas wisi eget nunc. Nam feugiat lacus vel est. Curabitur consectetuer.

Suspendisse vel felis. Ut lorem lorem, interdum eu, tincidunt sit amet, laoreet vitae, arcu. Aenean faucibus pede eu ante. Praesent enim elit, rutrum at, molestie non, nonummy vel, nisl. Ut lectus eros, malesuada sit amet, fermentum eu, sodales cursus, magna. Donec eu purus. Quisque vehicula, urna sed ultricies auctor, pede lorem egestas dui, et convallis elit erat sed nulla. Donec luctus. Curabitur et nunc. Aliquam dolor odio, commodo pretium, ultricies non, pharetra in, velit. Integer arcu est, nonummy in, fermentum faucibus, egestas vel, odio.

Sed commodo posuere pede. Mauris ut est. Ut quis purus. Sed ac odio. Sed vehicula hendrerit sem. Duis non odio. Morbi ut dui. Sed accumsan risus eget odio. In hac habitasse platea dictumst. Pellentesque non elit. Fusce sed justo eu urna porta tincidunt. Mauris felis odio, sollicitudin sed, volutpat a, ornare ac, erat. Morbi quis dolor. Donec pellentesque, erat ac sagittis semper, nunc dui lobortis purus, quis congue purus metus ultricies tellus. Proin et quam. Class aptent taciti sociosqu ad litora torquent per conubia nostra, per inceptos hymenaeos. Praesent sapien turpis, fermentum vel, eleifend faucibus, vehicula eu, lacus.

Pellentesque habitant morbi tristique senectus et netus et malesuada fames ac turpis egestas. Donec odio elit, dictum in, hendrerit sit amet, egestas sed, leo. Praesent feugiat sapien aliquet odio. Integer vitae justo. Aliquam vestibulum fringilla lorem. Sed neque lectus, consectetuer at, consectetuer sed, eleifend ac, lectus. Nulla facilisi. Pellentesque eget lectus. Proin eu metus. Sed porttitor. In hac habitasse platea dictumst. Suspendisse eu lectus. Ut mi mi, lacinia sit amet, placerat et, mollis vitae, dui. Sed ante tellus, tristique ut, iaculis eu, malesuada ac, dui. Mauris nibh leo, facilisis non, adipiscing quis, ultrices a, dui.

Morbi luctus, wisi viverra faucibus pretium, nibh est placerat odio, nec commodo wisi enim eget quam. Quisque libero justo, consectetuer a, feugiat vitae, porttitor eu, libero. Suspendisse sed mauris vitae elit sollicitudin malesuada. Maecenas ultricies eros sit amet ante. Ut venenatis velit. Maecenas sed mi eget dui varius euismod. Phasellus aliquet volutpat odio. Vestibulum ante ipsum primis in faucibus orci luctus et ultrices posuere cubilia Curae; Pellentesque sit amet pede ac sem eleifend consectetuer. Nullam elementum, urna vel imperdiet sodales, elit ipsum pharetra ligula, ac pretium ante justo a nulla. Curabitur tristique arcu eu metus. Vestibulum lectus. Proin mauris. Proin eu nunc eu urna hendrerit faucibus. Aliquam auctor, pede consequat laoreet varius, eros tellus scelerisque quam, pellentesque hendrerit ipsum dolor sed augue. Nulla nec lacus.

Suspendisse vitae elit. Aliquam arcu neque, ornare in, ullamcorper quis, commodo eu, libero. Fusce sagittis erat at erat tristique mollis. Maecenas sapien libero, molestie et, lobortis in, sodales eget, dui. Morbi ultrices rutrum lorem. Nam elementum ullamcorper leo. Morbi dui. Aliquam sagittis. Nunc placerat. Pellentesque tristique sodales est. Maecenas imperdiet lacinia velit. Cras non urna. Morbi eros pede, suscipit ac, varius vel, egestas non, eros. Praesent malesuada, diam id pretium elementum, eros sem dictum tortor, vel consectetuer odio sem sed wisi.

Figure 1 indicates the lifetime and average energy consumption for PEGASIS, PEGASIS-E, COSEN, ECBSN,IECBSN, and EAPHRN in case of static sink. We can see that the network lifetime for PEGASIS, PEGASIS-E, and IECBSN is increased with static sink at location $(50,300)$ and decreased when the sink is located near to the network center. However, the network lifetime for COSEN, ECBSN, and EAPHRN is decreased when the sink is located far away from the network center. On the other hand, the average energy consumption for all protocols is increased in case of sink location $(50,300)$ and decreased for sink locations $(50,50)$ and $(100,100)$; this is due to the increasing of the distance between the sink and the nodes implies increasing of consumed energy, which it can be observed from Equation 1

Lorem ipsum dolor sit amet, consectetuer adipiscing elit. Ut purus elit, vestibulum ut, placerat ac, adipiscing vitae, felis. Curabitur dictum gravida mauris. Nam arcu libero, nonummy eget, consectetuer id, vulputate a, magna. Donec vehicula augue eu neque. Pellentesque habitant morbi tristique senectus et netus et malesuada fames ac turpis egestas. Mauris ut leo. Cras viverra metus rhoncus sem. Nulla et lectus vestibulum urna fringilla ultrices. Phasellus eu tellus sit amet tortor gravida placerat. Integer sapien est, iaculis in, pretium quis, viverra ac, nunc. Praesent eget sem vel leo ultrices bibendum. Aenean faucibus. Morbi dolor nulla, malesuada eu, pulvinar at, mollis ac, nulla. Curabitur auctor semper nulla. Donec varius orci eget risus. Duis nibh mi, congue eu, accumsan eleifend, sagittis quis, diam. Duis eget orci sit amet orci dignissim rutrum.

Nam dui ligula, fringilla a, euismod sodales, sollicitudin vel, wisi. Morbi auctor lorem non justo. Nam lacus libero, pretium at, lobortis vitae, ultricies et, tellus. Donec aliquet, tortor sed accumsan bibendum, erat ligula aliquet magna, vitae ornare odio metus a mi. Morbi ac orci et nisl hendrerit mollis. Suspendisse ut massa. Cras nec ante. Pellentesque a nulla. Cum sociis natoque penatibus et magnis dis parturient montes, nascetur ridiculus mus. Aliquam tincidunt urna. Nulla ullamcorper vestibulum turpis. Pellentesque cursus luctus mauris. 
Fig. 1. Network lifetime and average energy consumption for a $200 \times 200$ network with BS locations at $(50,50),(100,100)$, and $(50,300)$.
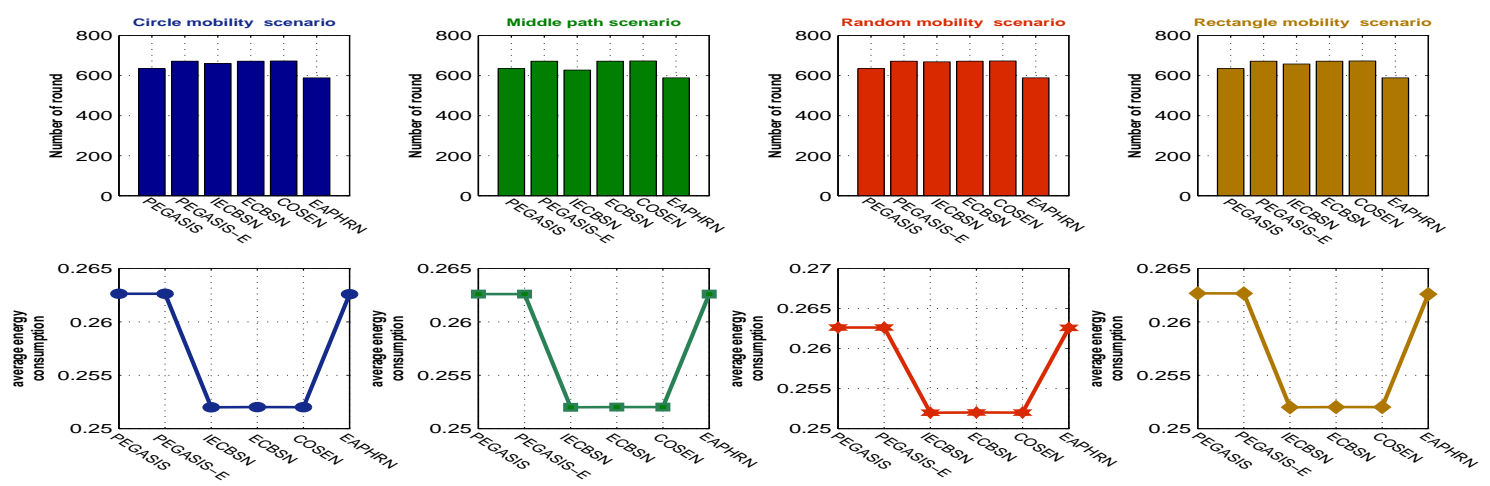

Fig. 2. Average Energy Consumption and Network lifetime for a $200 \times 200$ network with sink is varied at different locations according to different mobility scenarios (random and predetermined).

Nulla malesuada porttitor diam. Donec felis erat, congue non, volutpat at, tincidunt tristique, libero. Vivamus viverra fermentum felis. Donec nonummy pellentesque ante. Phasellus adipiscing semper elit. Proin fermentum massa ac quam. Sed diam turpis, molestie vitae, placerat a, molestie nec, leo. Maecenas lacinia. Nam ipsum ligula, eleifend at, accumsan nec, suscipit a, ipsum. Morbi blandit ligula feugiat magna. Nunc eleifend consequat lorem. Sed lacinia nulla vitae enim. Pellentesque tincidunt purus vel magna. Integer non enim. Praesent euismod nunc eu purus. Donec bibendum quam in tellus. Nullam cursus pulvinar lectus. Donec et mi. Nam vulputate metus eu enim. Vestibulum pellentesque felis eu massa.

Quisque ullamcorper placerat ipsum. Cras nibh. Morbi vel justo vitae lacus tincidunt ultrices. Lorem ipsum dolor sit amet, consectetuer adipiscing elit. In hac habitasse platea dictumst. Integer tempus convallis augue. Etiam facilisis. Nunc elementum fermentum wisi. Aenean placerat. Ut imperdiet, enim sed gravida sollicitudin, felis odio placerat quam, ac pulvinar elit purus eget enim. Nunc vitae tortor. Proin tempus nibh sit amet nisl. Vivamus quis tortor vitae risus porta vehicula.

Fusce mauris. Vestibulum luctus nibh at lectus. Sed bibendum, nulla a faucibus semper, leo velit ultricies tellus, ac venenatis arcu wisi vel nisl. Vestibulum diam. Aliquam pellentesque, augue quis sagittis posuere, turpis lacus congue quam, in hendrerit risus eros eget felis. Maecenas eget erat in sapien mattis porttitor. Vestibulum porttitor. Nulla facilisi. Sed a turpis eu lacus commodo facilisis. Morbi fringilla, wisi in dignissim interdum, justo lectus sagittis dui, et vehicula libero dui cursus dui. Mauris tempor ligula sed lacus. Duis cursus enim ut augue. Cras ac magna. Cras nulla. Nulla egestas. Curabitur a leo. Quisque egestas wisi eget nunc. Nam feugiat lacus vel est. Curabitur consectetuer.

Suspendisse vel felis. Ut lorem lorem, interdum eu, tincidunt sit amet, laoreet vitae, arcu. Aenean faucibus pede eu ante. Praesent enim elit, rutrum at, molestie non, nonummy vel, nisl. Ut lectus eros, malesuada sit amet, fermentum eu, sodales cursus, magna. Donec eu purus. Quisque vehicula, urna sed ultricies auctor, pede lorem egestas dui, et convallis elit erat sed nulla. Donec luctus. Curabitur et nunc. Aliquam dolor odio, commodo pretium, ultricies non, pharetra in, velit. Integer arcu est, nonummy in, fermentum faucibus, egestas vel, odio.

Sed commodo posuere pede. Mauris ut est. Ut quis purus. Sed ac odio. Sed vehicula hendrerit sem. Duis non odio. Morbi ut dui. Sed accumsan risus eget odio. In hac habitasse platea dictumst. Pellentesque non elit. Fusce sed justo eu urna porta tincidunt. Mauris felis odio, sollicitudin sed, volutpat a, ornare ac, erat. Morbi quis dolor. Donec pellentesque, erat ac sagittis semper, nunc dui lobortis purus, quis congue purus metus ultricies tellus. Proin et quam. Class aptent taciti sociosqu ad litora torquent per conubia nostra, per inceptos hymenaeos. Praesent sapien turpis, fermentum vel, eleifend faucibus, vehicula eu, lacus.

Pellentesque habitant morbi tristique senectus et netus et malesuada fames ac turpis egestas. Donec odio elit, dictum in, hendrerit sit amet, egestas sed, leo. Praesent feugiat sapien aliquet odio. Integer vitae justo. Aliquam vestibulum fringilla lorem. Sed neque lectus, 
consectetuer at, consectetuer sed, eleifend ac, lectus. Nulla facilisi. Pellentesque eget lectus. Proin eu metus. Sed porttitor. In hac habitasse platea dictumst. Suspendisse eu lectus. Ut mi mi, lacinia sit amet, placerat et, mollis vitae, dui. Sed ante tellus, tristique ut, iaculis eu, malesuada ac, dui. Mauris nibh leo, facilisis non, adipiscing quis, ultrices a, dui.

Morbi luctus, wisi viverra faucibus pretium, nibh est placerat odio, nec commodo wisi enim eget quam. Quisque libero justo, consectetuer a, feugiat vitae, porttitor eu, libero. Suspendisse sed mauris vitae elit sollicitudin malesuada. Maecenas ultricies eros sit amet ante. Ut venenatis velit. Maecenas sed mi eget dui varius euismod. Phasellus aliquet volutpat odio. Vestibulum ante ipsum primis in faucibus orci luctus et ultrices posuere cubilia Curae; Pellentesque sit amet pede ac sem eleifend consectetuer. Nullam elementum, urna vel imperdiet sodales, elit ipsum pharetra ligula, ac pretium ante justo a nulla. Curabitur tristique arcu eu metus. Vestibulum lectus. Proin mauris. Proin eu nunc eu urna hendrerit faucibus. Aliquam auctor, pede consequat laoreet varius, eros tellus scelerisque quam, pellentesque hendrerit ipsum dolor sed augue. Nulla nec lacus.

Suspendisse vitae elit. Aliquam arcu neque, ornare in, ullamcorper quis, commodo eu, libero. Fusce sagittis erat at erat tristique mollis. Maecenas sapien libero, molestie et, lobortis in, sodales eget, dui. Morbi ultrices rutrum lorem. Nam elementum ullamcorper leo. Morbi dui. Aliquam sagittis. Nunc placerat. Pellentesque tristique sodales est. Maecenas imperdiet lacinia velit. Cras non urna. Morbi eros pede, suscipit ac, varius vel, egestas non, eros. Praesent malesuada, diam id pretium elementum, eros sem dictum tortor, vel consectetuer odio sem sed wisi.

Figure 2 shows the lifetime and average energy consumption for PEGASIS, PEGASIS-E, COSEN, ECBSN,IECBSN, and EAPHRN in case of mobile sink. We can see that the average energy consumption in PEGASIS, PEGASIS-E, COSEN, ECBSN,IECBSN, and EAPHRN is decreased in all mobility scenarios. We can also observe that the network lifetime in PEGASIS, PEGASIS-E, COSEN, and ECBSN is decreased in all mobility scenarios. But on the other hand, we find that the network lifetime in IECBSN is increased in case of rectangle, middle path, and circle sink mobility scenarios compared to the static sink with locations $(50,50)$ and $(100,100)$. Furthermore, the network lifetime in IECBSN with random mobility scenario is decreased slightly compared to the static sink with location $(50,300)$. Only EAPHRN gives an increasing in the network lifetime in all mobility scenarios compared to its results in static sink.

By comparing network lifetime of all protocols in both cases, mobile sink and static sink, it is concluded that network lifetime of IECBSN and EAPHRN is increased in case of mobile sink. In addition to that the average consumed energy for all protocols is decreased in case of mobile sink. Only EAPHRN and IECBSN performs better in mobile sink and all other protocols give good results in static sink.

\section{CONCLUSION}

In this paper, we have introduced the mobility of sink in all proposed protocols, PEGASIS, PEGASIS-E, IECBN, ECBN, COSEN, and EAPHRN to compare their performances. We have introduced two scenarios are discussed to compare the performances of chain based routing protocols; in first scenario static sink is used and in the later one mobile sink is used. We have proposed different mobility scenarios, random, circle, middle path and rectangle mobility. The simulation results show that for various mobility scenarios EAPHRN and IECBSN perform better and all other protocols perform better in case of static sink. In our future work we aim to incorporate multiple sinks in the network and compare the performances of chain based routing protocols. We plan also to apply some heuristics techniques to find the minimum energy consumption paths for mobile sink.

\section{REFERENCES}

[1] Samia A. Ali and Shreen K. Refaay. Chain-chain based routing protocol. IJCSI International Journal of Computer Science, 8(2):1694-0814, May 2011.

[2] Ma J Li N-Khan I Chen C. Hums Bi Y, Sun L. An autonomous moving strategy in data gathering sensor networks. J EURASIP Journal On Wireless Communication and Networking, 15, 2007.

[3] P. Mitra C. Ok, S. Lee and S. Kumara. Distributed routing in wireless sensor networks using energy welfare metric. Information Sciences, 180(9):1656-1670, 2010.

[4] J. Heidemann D. Estrin, R. Govindan and S. Kumar. Next century challenges: scalable coordination in sensor networks. Proceedings of the 5th Annual ACM/IEEE International Conference on Mobile Computing and Networking, pages 263-270, 1999.

[5] Ekici E Ozguner F-Lee C. Gu Y, Bozdag D. Partitioning based mobile element scheduling in wireless sensor networks. The 2nd Annual IEEE Communications Society Conference on Sensor and Ad Hoc Communications and Networks, pages 26-29, 2005.

[6] A Sleit W Almobaideen H Alhasan, M Qatawneh. Eaphrn: energy-aware pegasis-based hierarchal routing protocol for wireless sensor networks. Journal of American Science, 2011.

[7] A. Chen J. Albowitz and L. Zhang. Recursive postion estimation in sensor networks. ICNP'01, 2001.

[8] Ain Q. Khan M. A. Javaid-Akmal Khan Z. A. Javaid, Nadeem and U. Qasim. On sink mobility trajectory in clustering routing protocols in wsns. The 25th IEEE International RealTime Systems Symposium, 2013.

[9] V. Cheung S.-H.G. Chan K.-F.S. Wong, I.W. Tsang and J.T. Kwok. Position estimation for wireless sensor networks. Proceedings of the IEEE Global Telecommunications Conference (GLOBECOM 2005), Nov 2005. http://www.cs.ust.hk/ jamesk/papers/globecom05.pdf.

[10] Murat Karakaya. Dynamic model for efficient data collection in wireless sensor networks with mobile sink. IJCST, 3(1):10, March 2012.

[11] Murat Karakaya. Deadline-aware energy-efficient query scheduling in wireless sensor networks with mobile sink. The Scientific World Journal, page 10, 2013.

[12] S. Lindsey and C. Raghavendra. Pegasis: Power efficient gathering in sensor information systems. Aerospace Conference Proceedings, 3:1125 - 1130, 2002.

[13] G. A. Di-Caro M. Saleem and M. Farooq. Swarm intelligence based routing protocol for wireless sensor networks: Survey and future directions. Information Sciences, 181(20):4597-4624, 2011.

[14] Shilpa Mahajan and Jyoteesh Malhotra. Enhanced chain technique based data collection sensor network. International Journal of Computer Science, 8:83-87, 2011.

[15] Chang-jiang J-Ying Z. Min X, Wei-ren S. Energy efficient clustering algorithm for maximizing lifetime of wireless 
sensor networks. J AEU-International Journal of Electronics and Communications, 64:289298, 2010.

[16] Hamid Reza NAJI. Moulood HEIDARI, Akbar NOORIEMAMZADE. Effect of using mobile sink and clustering on energy consumption in wireless sensor networks. Turk J Elec Eng and Comp Sci, page 1 16, 2015.

[17] AKM Ahsanul Nahdia Abassum, Quazi Ehsanul Kabir Haque Mamun and Yoshiyori Urano. A chain oriented data collection protocol for energy-aware and delay-constrained wsn. African Journal of Information and Communication Technology, 2(3):11, 2006.

[18] D. Niculescu. Ad hoc positioning system. Proceeding of CLOBECOM, November 2001.

[19] G. P. Hancke S. Chinnappen-Rimer. Calculation of an optimum mobile sink path in a wireless sensor network,. Wireless Sensor Networks - Technology and Protocols, 2012.

[20] S. S. Aurlio S. P. Srgio and A. Perkusich. Broadcast routing in wireless sensor networks with dynamic power management and multi-coverage backbones. Information Sciences, 180(5):653-663, 2010.

[21] Jyoteesh Malhotra Shilpa Mahajan and Sandeep Sharma. Improved enhanced chain based energy efficient wireless sensor network. Wireless Sensor Network, pages 84-89, 2013.

[22] M P Singh Shio Kumar Singh and D K Singh. Routing protocols in wireless sensor networks - a survey. International Journal of Computer Science and Engineering Survey (IJCSES), 1(2), 2010.

[23] Srivastava M. Somasundara A, Romamoorthy A. Mobile element scheduling for efficient data collection on wireless sensor. The 25th IEEE International Real- Time Systems Symposium, page 296 305, Dec 2004.

[24] Guo S. Guo M. Ma Tang F., You I. A chain-cluster based routing algorithm for wireless sensor networks. journal of intelligent manufacturing, 23(4):1305-1313, 2012.

[25] Ajay K. Sharma Vibha Nehra. Pegasis-e: Power efficient gathering in sensor information system extended. Global Journal of Computer Science and Technology Network, Web and Security, 13(15), 2013.

[26] A. Chandrakasan W. R. Heinzelman and H. Balakrishnan. Energy-efficient communication protocol for wireless microsensor networks. Proceedings of the 33rd Hawaii International Conference on System Sciences, pages 1-10, 2000.

[27] S. Boudjit Y. Faheem and K. Chen. Data dissemination strategies in mobile sink wireless sensor networks: A survey. Proceedings of the 2nd IFIP conference on Wireless days (WD'09), 2009.

[28] Yongchang Yu and Yichang Song. An energy-efficient chain-based routing protocol in wireless sensor network. Computer Application and System Modeling (ICCASM), 11:486-489, 2010 